\title{
Report from Accident and Emergency departments
}

Psychiatric Services to Accident and Emergency Departments. Report of a Joint Working Party of the Royal College of Psychiatrists and the British Association for Accident and Emergency Medicine.

This report discusses aspects of the psychiatric service required in the Accident and Emergency (A\&E) Department. It discusses the need for psychiatric support, staffing and facilities necessary and also contains sections on education, the Mental Health Act, and service evaluation.

Although in some areas community psychiatric services offer 24-hour a day, seven days a week emergency cover, in many others the A\&E Department is the main out-of-hours crisis intervention service. A\&E staff, therefore, feel an increasing need to have some psychiatric guidance and the availability of prompt advice.

The report makes recommendations in the areas of staffing, facilities, education and the application of the Mental Health Act, particularly section 136, in England and Wales.

This report is available from The Royal College of Psychiatrists (please quote CR43) and is priced at £5.00. (Telephone: 01712352351 ext. 146).

\section{\% The Analysis of Hysteria Second Edition \\ Understanding Conversion and Dissociation By Harold Merskey}

This book is a substantial update and enlargement of the first edition, which received exceptionally good reviews when first published in 1979. It provides a survey of the topics which have been included under the name of hysteria and which are still of importance under the terms conversion and dissociation. Current concepts of repression, including the common modern problems of "multiple personality disorder" and "recovered memory" are discussed in detail. The whole range of hysterical phenomena is covered, from classical paralyses and blindness to questions about hysterical personality and epidemic hysteria. £30.00, 504pp., Hardback, 1995, ISBN 0902241885

Available from bookshops and from the Publications Department, Royal College of Psychiatrists, 17 Belgrave Square, London SW1X 8PG (Tel. 0171-235 2351, extension 146)

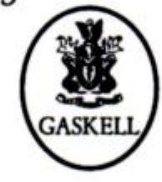

